\title{
Hepatoprotective and Antioxidant Capacity of Clerodendrum paniculatum Flower Extracts Against Carbon tetrachloride-Induced Hepatotoxicity in Rats
}

\author{
Remya Kopilakkal a, Kaushik Chanda ${ }^{\text {a*}}$, and Musuvathi Motilal Balamuralib*
}

aDepartment of Chemistry, School of Advanced Sciences, Vellore Institute of Technology, Vellore - 632 014, Tamil Nadu, India

bDivision of Chemistry, School of Advanced Sciences, Vellore Institute of Technology, Chennai campus, Vandalur - Kelambakkam Road, Chennai - 600 127, Tamil Nadu, India

E-mail: chandakaushik1@gmail.com

mmbala@gmail.com

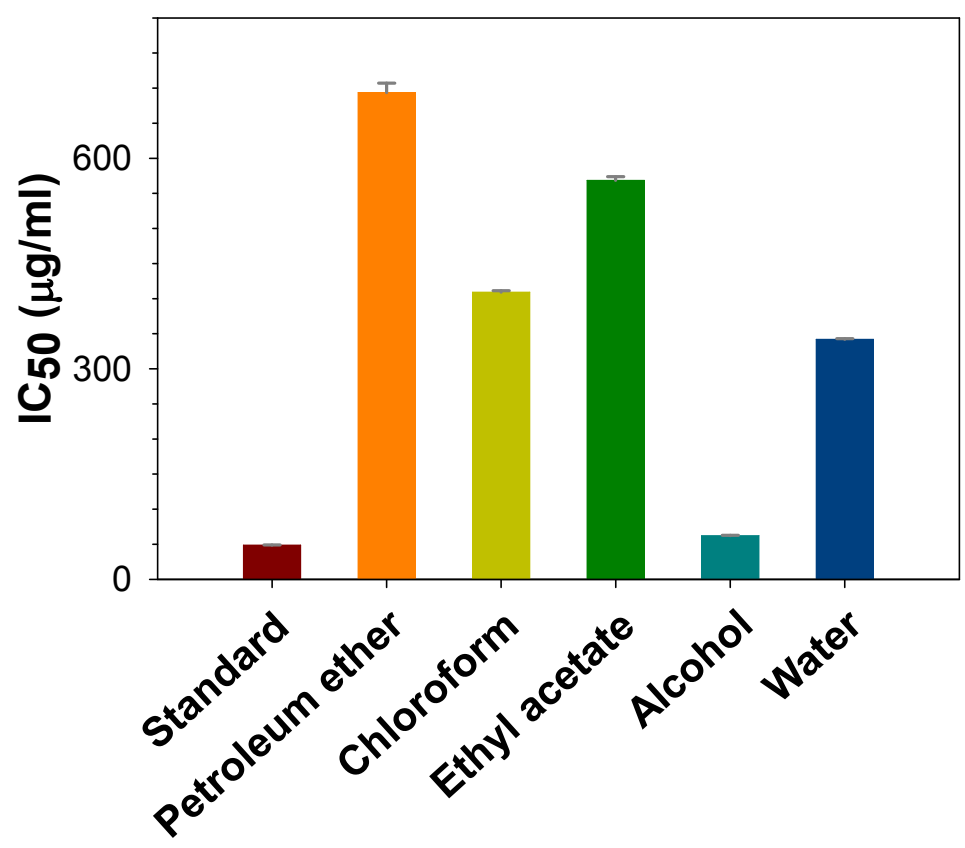

Figure S1. Bar graph representing the antioxidant activity of various extracts of C.paniculatum flower by DPPH method and expressed in terms of their $\mathrm{IC}_{50}(\mu \mathrm{g} / \mathrm{ml})$ 


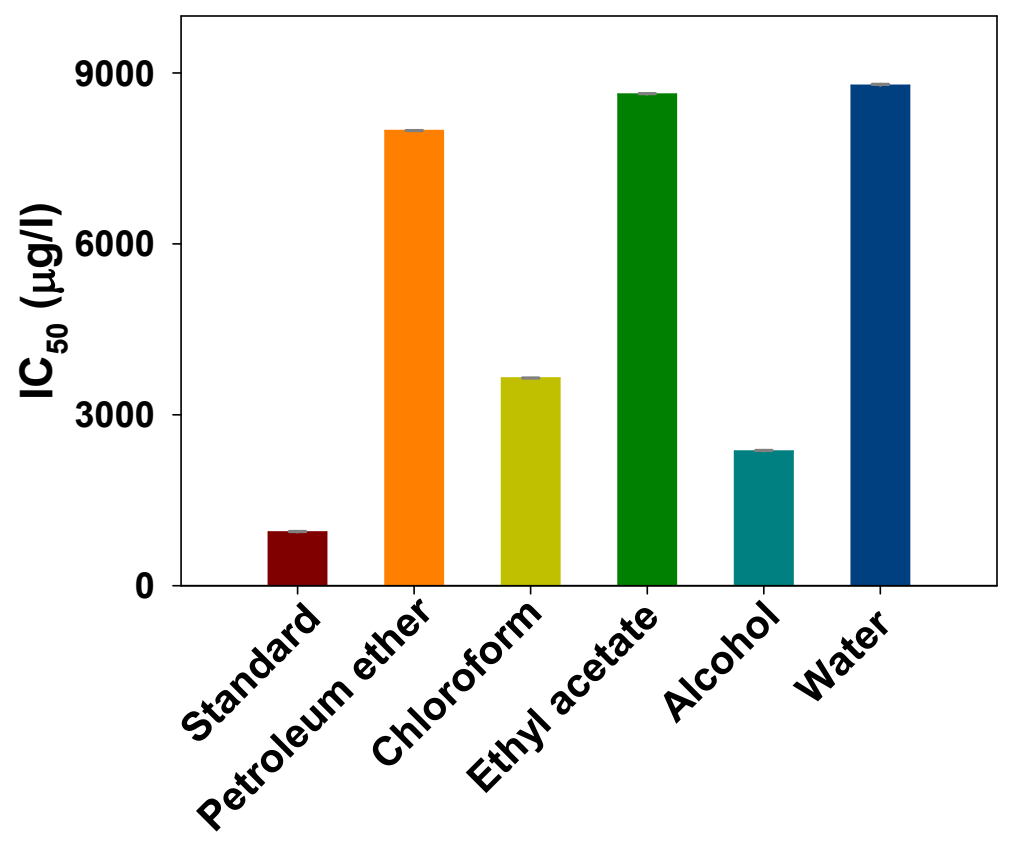

Figure S2. Bar graph representing the antioxidant activity of C.paniculatum flower extracts by ABTS assay and expressed in terms of their $\mathrm{IC}_{50}(\mu \mathrm{g} / \mathrm{ml})$

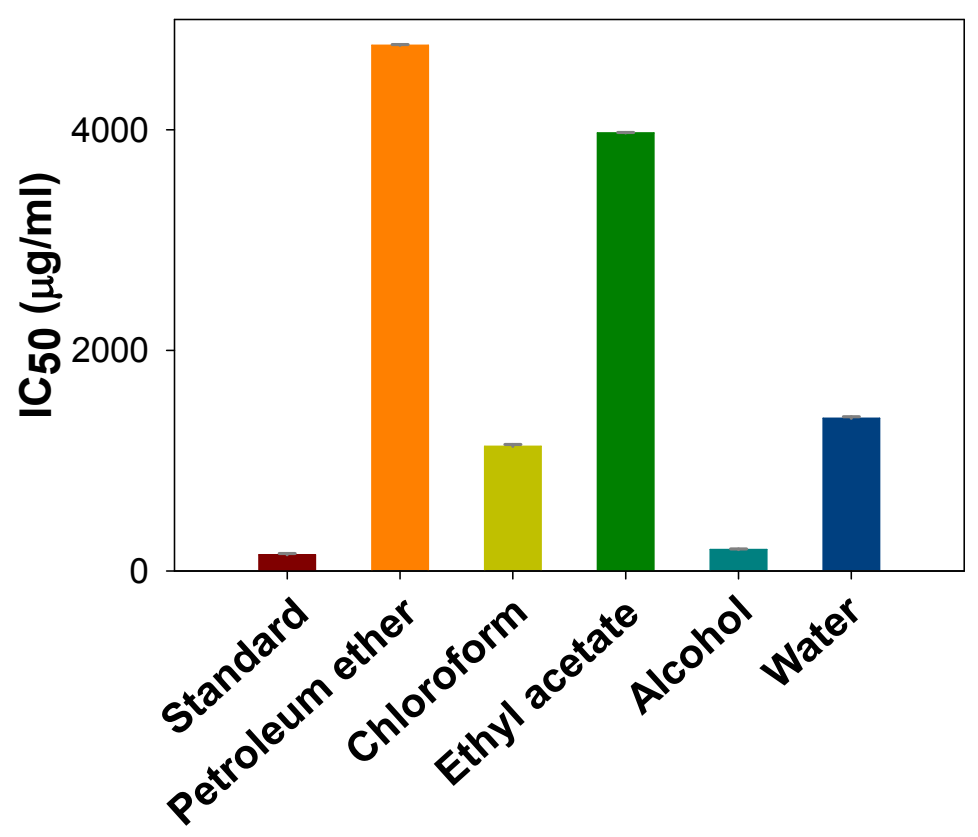

Figure S3. Bar graph depicting the nitric oxide radical inhibitory assay of C.paniculatum flower extracts. 
(a)

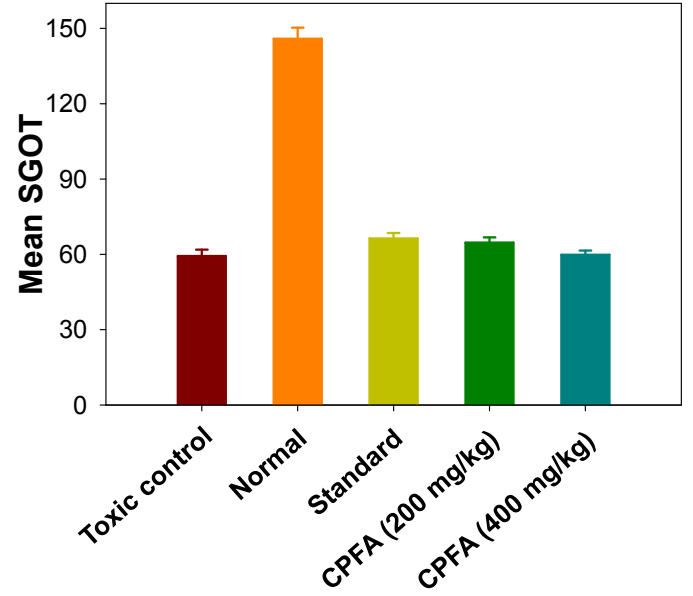

(c)

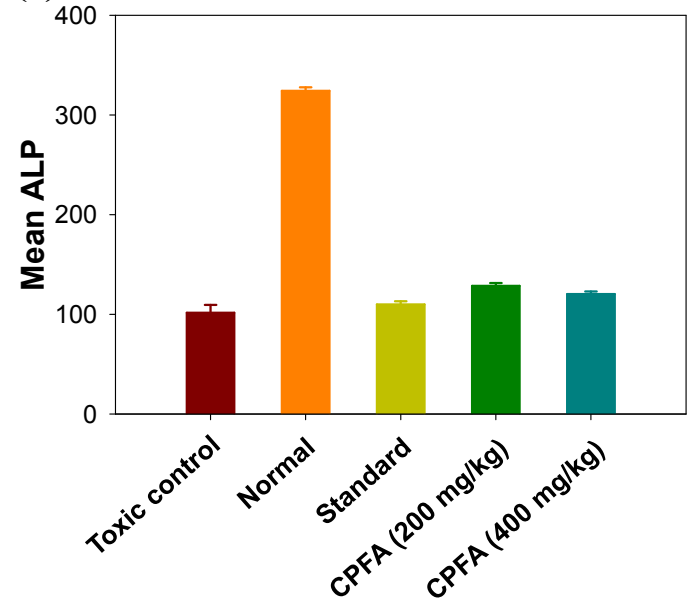

(e)

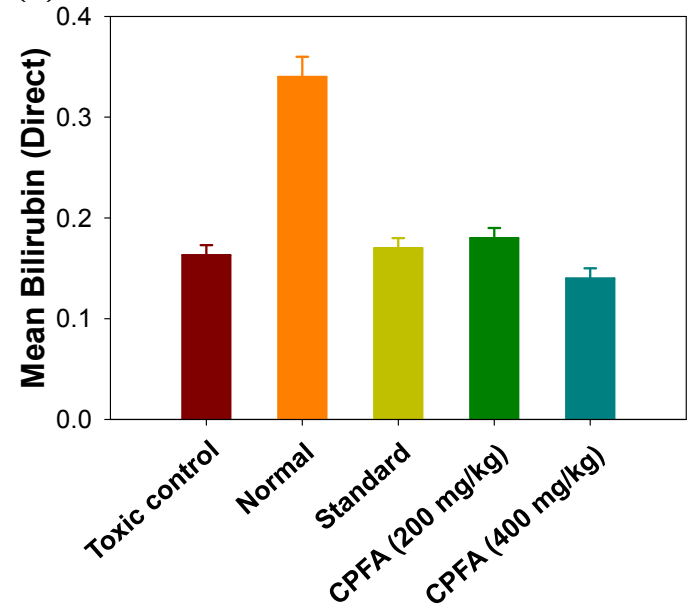

(b)

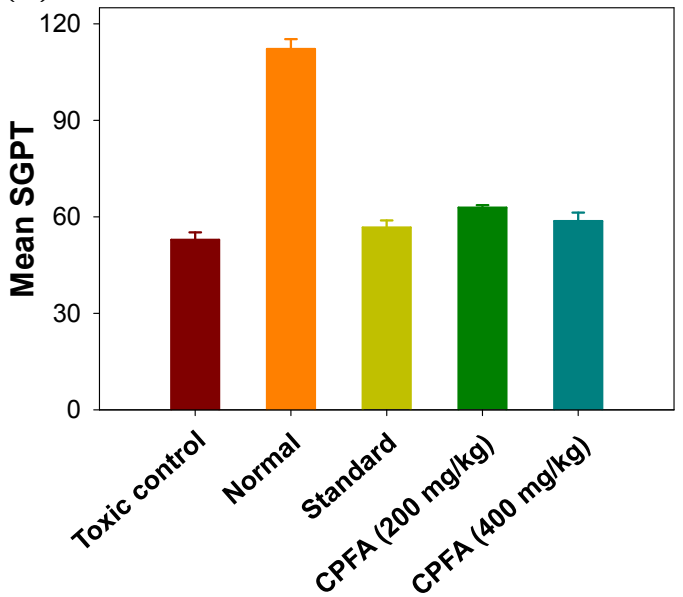

(d)

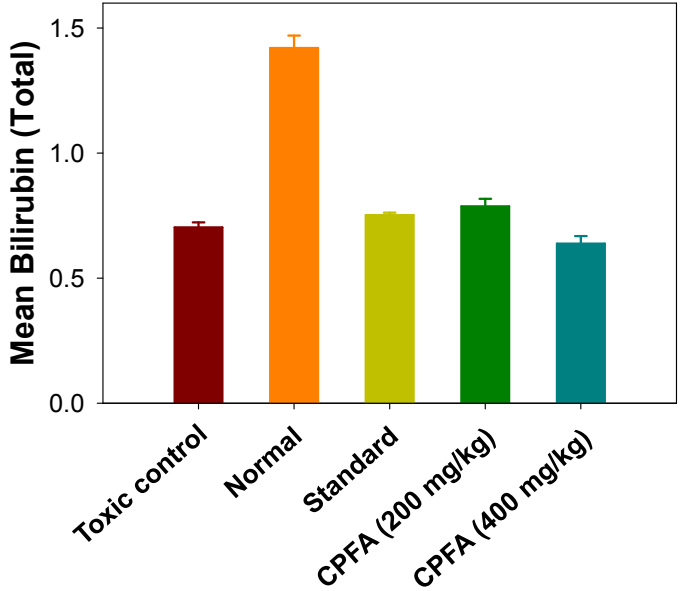

(f)

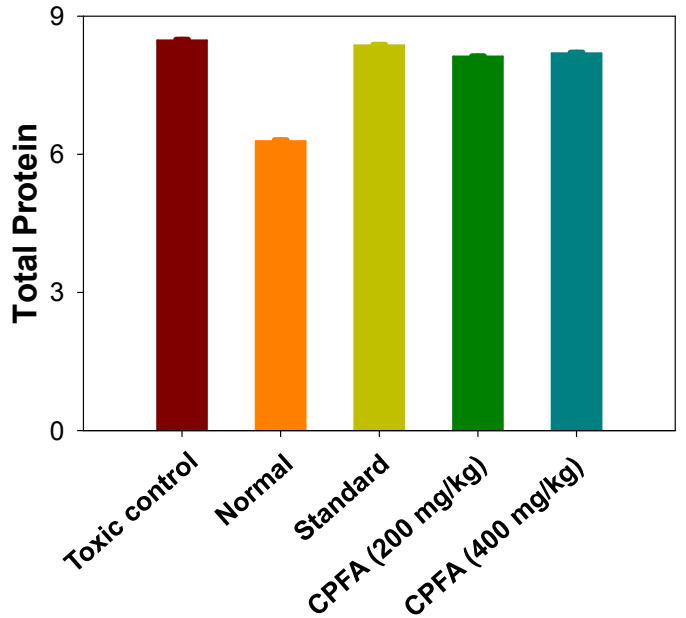

Figure S4. Effect of $\mathrm{CCl}_{4}$ intoxication and pretreatment with $C$. paniculatum flower alcoholic extract on serum enzyme levels of (a) SGOT, (b) SGPT, (c) ALP, (d) total and (e) direct bilirubin, f) total protein content. Results are compared to positive control group $\left(\mathrm{CCl}_{4}\right.$ intoxicated). Values are mean \pm S.E.M $(n=6)$. 


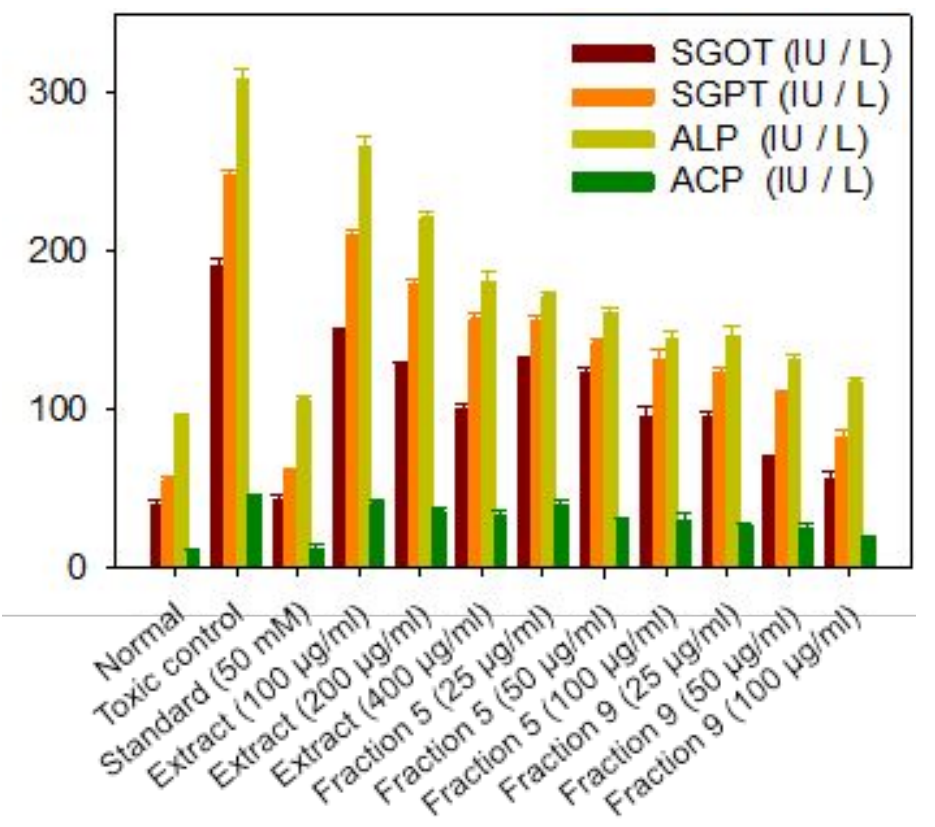

Figure S5. In vitro hepatoprotective evaluation of $C$. paniculatum flower alcoholic extract isolated fractions on serum enzyme levels of SGOT, SGPT, ALP and ACP. Results are compared to positive control group $\left(\mathrm{CCl}_{4}\right.$ intoxicated $)$. Values are mean $\pm \mathrm{S} . \mathrm{D}(\mathrm{n}=3)$. 


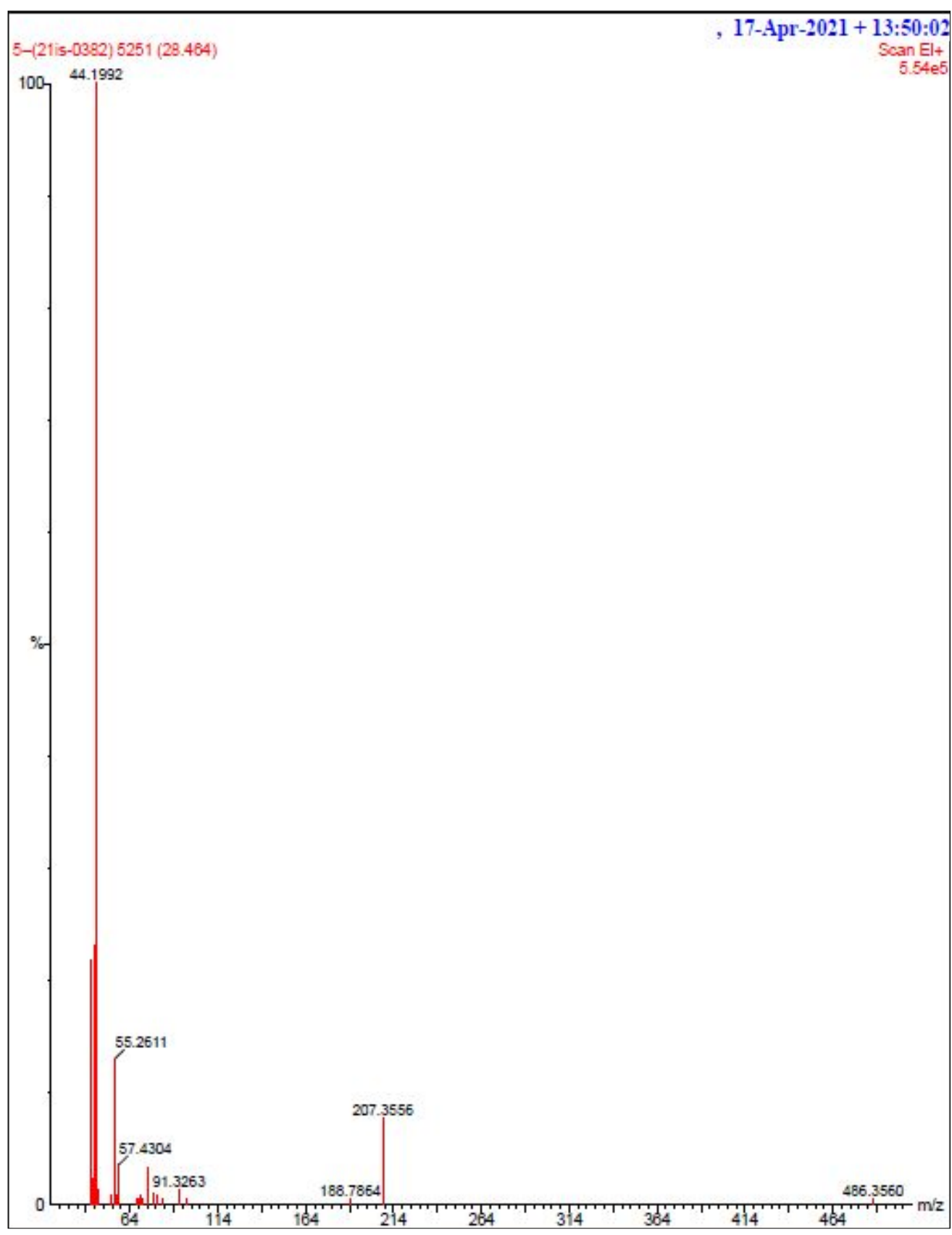

Figure S6. GC-MS chromatogram of fraction 5 depicting the presence of Quinovic acid 


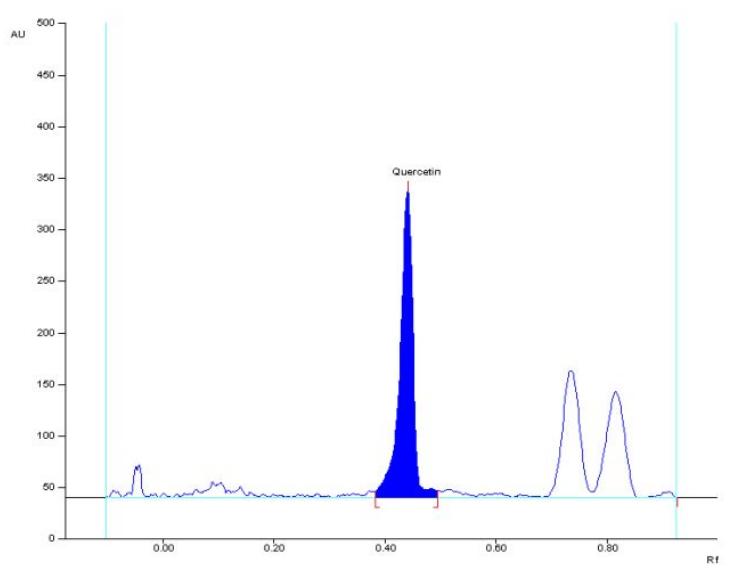

A. Standard Quercetin

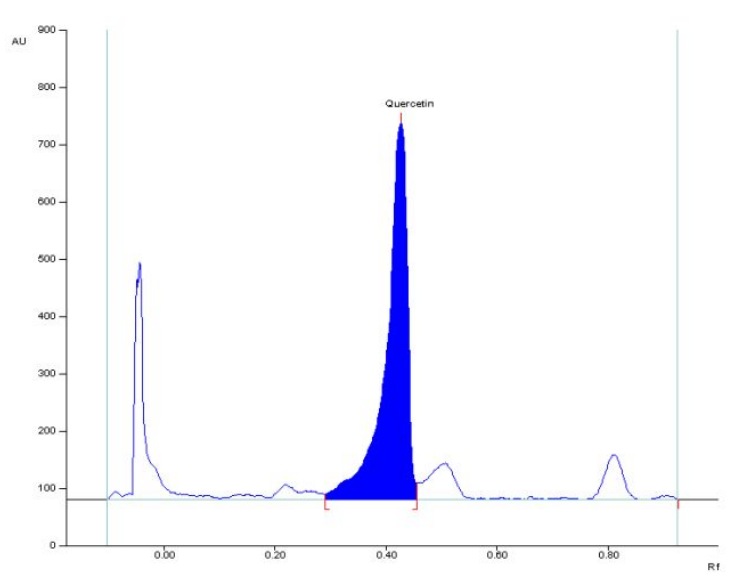

C. Fraction 5

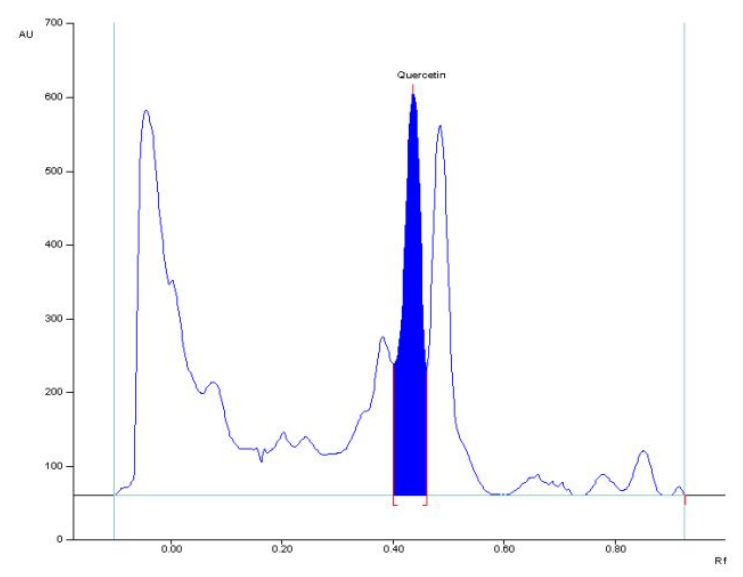

B. Alcoholic extract

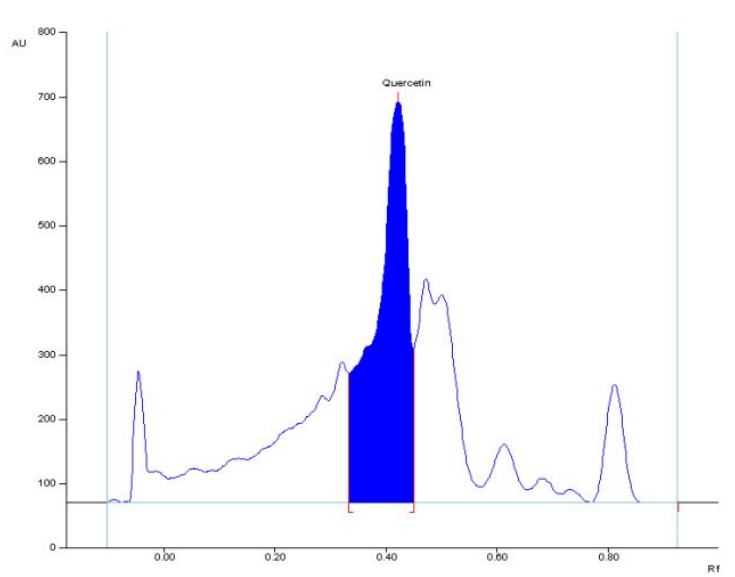

D. Fraction 9

Figure S7. HPTLC chromatogram of A. standard Quercetin, B. Alcoholic extract of $C$. paniculatum, C. Fraction 5 and D. Fraction 9 as observed under $254 \mathrm{~nm}$. 